\title{
LUGARES DO MATERNO EM COMO ÁGUA PARA CHOCOLATE, DE LAURA ESQUIVEL
}

\author{
Jenison Alisson Santos \\ Mestrando em Letras pela UFPB \\ jenison.alisson@gmail.com
}

\section{RESUMO}

Laura Esquivel (1993), em seu romance Como água para chocolate, apresenta diferentes subjetividades do sujeito feminino, desenvolvidas a partir do discurso gastronômico, ao narrar a história de gerações de mulheres da família De la Garza. No presente artigo, analisamos como a autora representa diversos lugares do materno - especialmente associados ao espaço da cozinha e à atividade de nutrição, tanto alimentar quando afetiva e como tais lugares podem ser percebidos como opressores ou como uma posição para a subversão de convenções sociais. Para tanto, nosso referencial teórico é composto por Badinter (1995), Beauvoir (1967), Butler (2016) e Xavier (1998), entre outros.

Palavras-chave: maternidade, Como água para chocolate, Laura Esquivel.

\begin{abstract}
In the novel Like water for chocolate (1993), Laura Esquivel portrays diverse female subjectivities, established through a gastronomic discourse, while narrating the lives of women from few generations of the De la Garza family. In this article, we seek to trace how the author elaborates on the different places of motherhood closely articulated with the space of the kitchen and with the activity of nurturing, both nutritional and affective - and how those places may be taken as oppressive or may offer a position to subvert social conventions. For this purpose, our theoretical framework is constituted by Badinter (1995), Beauvoir (1967), Butler (2016) and Xavier (1998), among others.
\end{abstract}

Keywords: motherhood, Like water for chocolate, Laura Esquivel.

Como água para chocolate, publicado em 1989 , é o primeiro romance da escritora mexicana Laura Esquivel. Nele, acompanhamos a história de Tita de La Garza, uma jovem mexicana imersa no mundo da cozinha uma vez que sua mãe a proíbe de casar-se com o homem que ela ama. Esquivel relata a jornada de Tita de sua mais tenra idade até o fim de sua vida, contando como a protagonista gradualmente se rebelou contra o autoritarismo de sua mãe. Críticos e leitores ao redor do mundo têm recebido de forma positiva a maneira 
inventiva como a autora mescla receitas, o contar de histórias e uma visão alternativa do México antes, durante e após a Revolução Mexicana. Construindo uma narrativa a partir de ferramentas características do fenômeno contemporâneo da metaficção, Esquivel criou uma fabulação de amor e morte, uma cativante jornada de mulheres em busca de suas subjetividades e transformação - tendo como fio condutor dos desdobramentos promovidos a presença do preparo e do consumo de alimentos.

Nessa narrativa, em meio a tantas questões sobre a(s) subjetividade(s) feminina(s), chama atenção a representação de diversos lugares do materno. Mais precisamente, Esquivel demonstra que a noção de maternidade enraizada na sociedade Ocidental moderna não se configura como algo natural e inato ao sujeito mulher, mas é concebida através de construtos sociais calcados no machismo, na misoginia e na violência contra a mulher. Nesse sentido, no presente artigo, objetivamos analisar como a autora representou esses diversos lugares do materno - especialmente associados ao espaço da cozinha e à atividade de nutrição, tanto alimentar quando afetiva - e como tais lugares podem ser percebidos como opressores ou como uma posição para a subversão de convenções sociais.

Para tanto, em um primeiro momento, apresentaremos algumas das principais discussões teóricas sobre o fenômeno da maternidade, surgidas em meio ao universo de teóricas feministas. A seguir, analisaremos a questão da maternidade e os lugares do materno em Como água para chocolate.

Elisabeth Badinter (1985), ao fazer um apanhado histórico em Um amor conquistado: o mito do amor materno, afiança que por volta de vinte e uma mil crianças nascem na Paris do século XVIII, das quais “[...] apenas mil são amamentadas pela mãe. Outras mil, privilegiadas, 
são amamentadas por amas-de-leite residentes. Todas as outras deixam o seio materno para serem criadas no domicílio mais ou menos distante de uma ama mercenária" ( p. 19). Tais estatísticas provocam na filósofa o questionamento não da noção de amor materno - como o subtítulo de seu estudo pode levar a acreditar -, mas a maneira como a sociedade falocêntrica moderna incube ao sujeito mulher a ideia de maternidade intrínseca, que subjuga tal sujeito ao lugar do materno como o agente principal no cuidado de sua prole, de forma passiva e idealizada.

Em seu estudo, Badinter (1985) defende que a concepção de instinto materno é a consequência de um construto social que estabelece parâmetros de comportamentos e responsabilidades, que precisariam ser performados (BUTLER, 2016) pelas mulheres em relação a seus filhos. Percebemos que sua tese afiança um questionamento levantado por Beauvoir (1967), em $O$ segundo sexo: 2, a experiência vivida, quando a filósofa francesa afirma que "[...] não existe instinto materno: a palavra não se aplica em nenhum caso à espécie humana. A atitude da mãe é definida pelo conjunto de sua situação e pela maneira por que a assume. É [...] extremamente variável" (p. 277-8).

Percebemos, ao ler Um amor conquistado, que "com base, em grande parte, em ideias freudianas vulgarizadas, as mulheres foram condicionadas a não ser senão mães devotas e mulheres do lar" (ROCHA-COUTINHO, 1994, p. 44), assim fazendo com que o sujeito mulher possuísse cada vez menos autonomia e lugar de fala na esfera pública da sociedade, transformando a noção de maternidade em um modelo de opressão e silenciamento. $\mathrm{Na}$ cultura ocidental contemporânea, podemos perceber que, mesmo após décadas em que os estudos de Badinter (1985) e Beauvoir (1967) foram publicados como forma de denúncia à 
pratica violenta da maternidade enquanto locus inerente do sujeito mulher, a sociedade ainda faz com que aquelas que rejeitam desempenhar tal papel sintam-se deslocadas da comunidade.

Beauvoir (1967) reforça tal argumento ao asseverar que, mesmo vivendo em um corpo social virtualmente progressista e que promove a reivindicação de direitos iguais para todos, os sujeitos mulher ainda se encontram à margem dessa comunidade, longe da esfera pública, passíveis de uma "uma servidão tanto mais pesada [...], confinadas na esfera feminina, Ihe hipertrofiaram a importância: transformaram em artes difíceis a toalete e os cuidados caseiros" (BEAUVOIR, 1967, p. 453). Notamos, então, que o sujeito mulher, segundo os parâmetros de uma sociedade opressora e falocêntrica, não está autorizado a exercer suas subjetividades de forma plena, conservando a hegemonia heteronormativa masculina, branca e de poder financeiro privilegiado que sustenta essa sociedade.

Ao rechaçar a premissa das relações de afeto entre a progenitora e seus filhos e apontar para a subordinação do sujeito mulher no tocante aos moldes que a sociedade falocêntrica impõe a maternidade como forma de "adestrar toda a sua descendência, mas também retirar práticas tradicionais, experimentada por tais mulheres, elementos para a construção de um modelo ideal" (DEL PRIORE, 2009, p. 95), Badinter (1985) denuncia o que chama de mito do amor materno, que reforça a ideologia da maternidade como um construto social intrínseco ao sujeito feminino.

Entendemos a correspondência entre a maternidade e o mito proporcionada pela filósofa como uma forma de transformar o que é construído socialmente a partir de ideologias e imposições como algo naturalmente genuíno, resistente à contestação, numa 
tentativa de "despolitizar o que é aparentemente político" (BARTHES, 2015, p. 54). Entretanto, tal movimento causa desdobramentos que, ao tentar transformar um discurso socialmente construído em algo que devemos receber com passividade, desperta em pensadoras e pensadores como Badinter (1985) o questionamento de que esse discurso apresenta, de fato, implicações políticas e ideológicas que existem para um fim específico no caso da maternidade, confinar o sujeito mulher em um lugar de subordinação, acomodando-a no espaço privado. E é precisamente a partir desse movimento de despolitização da maternidade ou de denúncia de tal discurso que Esquivel irá explorar em sua narrativa os lugares do materno, evidenciando como as relações de poder que circunscrevem esses lugares, envoltas em uma dissimulação mística, buscam despolitizar aquilo que é inerentemente ideológico.

Para tanto, iremos calcar nossos argumentos sobre a maternidade em relação a Como água para chocolate não especificamente sobre mães em seu sentido mais essencial embora tal problematização se fará presente -, mas acerca do sujeito mulher e os lugares do materno no que se refere às relações fronteiriças entre o que é tido por instintivo e aquilo que é construído a partir de laços afetivos e de circunstâncias, a partir da dicotomia daquilo que é inato em detrimento daquilo que é estabelecido através das relações interpessoais, e da associação entre o corpo do sujeito mulher e a maternidade.

Defendemos a relevância de tal problematização no romance visto que a autora, ao escrever uma narrativa que versa sobre as diversas dimensões das subjetividades do sujeito feminino, coloca em destaque os lugares do materno de forma a problematizar a percepção de maternidade como um dado inerente a este sujeito, e como a perpetuação da 
representação desse sujeito enquanto agente passivo do discurso da maternidade natural e apropriada pode trazer consequências nocivas a uma percepção mais complexa e multidimensional do sujeito mulher no imaginário sociocultural. Tal tensão se faz ostensiva, entendemos, não como a maneira que esse mito do amor materno (BADINTER, 1985) é concretizado e fossilizado na sociedade falocêntrica, mas é uma maneira de manifestar e de expor a forma como a violência imposta no sujeito mulher, a partir dessa ideologia, está enraizada não apenas em posições políticas socialmente construídas, mas está imbuído na própria linguagem (BUTLER, 2016).

Quando Woolf (2014) disserta, em Um teto todo seu, sobre a relevância da mulher ter um espaço que lhe pertença para poder colocar em prática o seu potencial artístico, a cozinha não é apontada como um espaço de empoderamento intelectual e criativo. Em um primeiro momento, o lugar em questão parece ser construído no imaginário da comunidade regida pelos princípios machistas em que "[...] o confinamento da mulher à esfera doméstica, que limita seu comportamento esperado e seu papel na sociedade, é antes condicionado pelo seu elemento social do que pelo biológico" (ROCHA-COUTINHO, 1994, p. 45), no qual a aparente sucessão de atividades repetitivas e sem carga criativa ou intelectual não oferece qualquer perspectiva de realização da subjetividade do sujeito mulher.

Entretanto, a cozinha, sendo um espaço privado socialmente designado para o sujeito mulher, acaba tornando-se um lugar favorável para que afetos sejam desenvolvidos entre as próprias mulheres - afetos esses que possuem a potencialidade para tornar-se catalizadores de transformação daquilo que foi pré-estabelecido por tal sociedade. Esquivel, Em Íntimas suculencias (2014, p. 15), diz que desde os primeiros anos de sua infância "[...] passei junto 
ao fogo da cozinha de minha mãe e de minha avó, vendo como essas sábias mulheres, ao entrar no recinto sagrado da cozinha, se convertiam em sacerdotisas [...]"1, e foi a partir dessa convivência com as matriarcas da família que ela aprendeu sobre a potência da união e do compartilhamento de saberes e afetos entre as mulheres, sobretudo das relações que emanam da cozinha.

Suas experiências pessoais em relação aos afetos que se desdobram nesse ambiente manifestam-se em Como água para chocolate, como podemos notar desde o primeiro capítulo da narrativa. A relação de Tita com o espaço da cozinha e com a comida tem seu início com Nacha, a cozinheira do rancho De la Garza. É a partir dos conhecimentos milenares de Nacha que Tita aprende não só que os alimentos têm como função primordial a nutrição, mas também possuem a capacidade de cura e de comunicação, e é a partir de tais ensinamentos que a cozinheira cria laços de afeto com a protagonista, tornando-se a figura materna que Tita não encontra em Mamãe Elena.

Em um contexto em que a Revolução transforma a sociedade sob a presença constante de tensão e hostilidade, a violência em suas mais diversas formas torna-se o meio mais comum de impor o controle (HEITMEYER, 2011). Mamãe Elena, caracterizada no romance como uma figura de poder, não se apresenta como liderança para uma comunidade de união e potência feminina, mas como um sujeito que reproduz um sistema retrogrado, tirânico e antirrevolucionário.

\footnotetext{
1 “[...] pasé junto al fuego de la cocina de mi madre y de mi abuela, viendo cómo estas sabias mujeres, al entrar en el recinto sagrado de la cocina, se convertían en sacerdotisas [...]". Tradução nossa, assim como as demais presente no artigo. 
Mamãe Elena, ao se encontrar sobrecarregada de novas incumbências como consequência da morte súbita de seu marido, rejeita sua filha mais nova no momento do nascimento e passa a enxergar Tita como uma serva, mantendo-a em um constante estado de opressão, confinamento e violência. Ao posicionar Mamãe Elena em uma situação onde ela renuncia Tita enquanto filha e enquanto sujeito e a deixa aos cuidados de Nacha, Esquivel nos aponta para uma nova configuração dos lugares do materno em que "transportar os aspectos cuidadores e nutridores da maternidade para figuras substitutas é uma forma de distanciar-se dos essencialismos ancorados na determinação biológica"2 (SCEATS, 2003, p. 15).

Continuando, é importante ressaltar a relevância do contexto histórico e como ele é significativo para estabelecer a pertinência do ponto de vista e das vivências do sujeito mulher na sociedade - em especial em se tratando de eventos históricos. A Revolução Mexicana, que demarca temporalmente o romance, influencia direta ou indiretamente as relações interpessoais entre as personagens da narrativa - especialmente Mamãe Elena e suas filhas.

Com pulso forte e preservação das tradições e costumes de sua família, Mamãe Elena representa a força opressora que ameaça a liberdade e livre arbítrio de Tita que, por sua vez, ao colocar em prática suas subjetividades e desafiar o poder ao encontrar a sua própria voz na cozinha, espelha os revolucionários. Ao proibir Tita de se casar com Pedro e obrigá-la a cuidar dela até a sua morte, Mamãe Elena perpetua compulsoriamente a dominação opressora sob sua filha.

\footnotetext{
2 "The transposing of the nurturing, feeding aspects of motherhood onto substitute figures is a way of avoiding a biologically determined essentialism".
} 
Ainda, se a matriarca dos De la Garza é descrita como alguém que "Indubitavelmente, tratando-se de partir, desmantelar, desmembrar, devastar, desjarretar, destruir, desbaratar ou desmamar alguma coisa, Mamãe Elena era mestra” (ESQUIVEL, 1993, p. 80) e que “[...] matava [galinhas] assim, de uma cutilada só, sem piedade" (ESQUIVEL, 1993, p. 39), reforçando a sua fronte tirânica. Por outro lado, Tita ganha voz e potência gradualmente no percurso da narrativa, aos poucos rompendo as amarras que a prendem aos costumes e tradições, evocando o desejo de solapar o status quo promovido pela Revolução.

A protagonista é impedida pela matriarca de viver um romance com seu amado, Pedro, em função de uma tradição familiar que dita que a filha mais nova ficará responsável por cuidar de sua mãe até o fim de seus dias. A forma agressiva com que Mamãe Elena submete Tita a uma vida de desafios e sofrimento acaba por destituir sua filha de sua integridade física e emocional, como exemplificado na passagem a seguir:

Ao lado da mãe, o que suas mãos tinham de fazer estava friamente determinado, não havia dúvidas. Tinha de levantar-se, vestir-se, acender o fogo do fogão, preparar o café da manhã, alimentar os animais, lavar os pratos, fazer as camas, preparar a comida, lavar os pratos, dia após dia, ano após ano. Sem parar um momento, sem pensar se isso era o que lhe correspondia (ESQUIVEL, 1993, p. 889).

É relevante apontar que Tita é condicionada pela mãe a servir a família, não porque o sujeito mulher é inerentemente competente ou mais apropriada a servir nesse espaço privado sob uma perspectiva estática e castradora intelectual e socialmente (ABARCA, 2006), mas porque Mamãe Elena perpetua uma visão de mundo conservadora, essencialista e opressora, calcada na tradição De la Garza. Entendemos que Tita, enquanto sujeito mulher, não está intrinsecamente associada ao espaço da cozinha, mas que foi submetida a tal 
propósito, doutrinada a cumprir aquele papel. Logo, notamos que, ao ser inserida nessa organização social, sua performance é uma consequência de sua condição, evidenciando "a noção de que pode haver uma 'verdade' do sexo, como Foucault a denomina ironicamente, [...] produzida precisamente pelas práticas reguladoras que geram identidades coerentes por via de uma matriz de normas de gênero coerentes" (BUTLER, 2016, p. 44), que perpetua uma visão de mundo retrógrada através dos preceitos acerca da identidade de gênero mantidos por uma sociedade falocêntrica.

A matriz normativa de que fala a teórica é a sistematização de uma heterossexualidade compulsória (BUTLER, 2016) que articula as convenções que buscam categorizar o sujeito mulher em papéis sociais que Ihes convém, fazendo com que tal sujeito ocupe lugares "inerentemente femininos", a exemplo do lugar materno, de cuidadora e provedora de alimento e afeto. Em Como água para chocolate, Esquivel denuncia a violência e a angústia que esse sistema machista fomenta no sujeito mulher ao colocar a sua protagonista no centro de uma prisão social provocada por um pacto coercitivo materializado pela tradição familiar, questionando "[...] este modelo familiar onde a mulher, condenada à imanência, fica reduzida ao espaço do privado" (XAVIER, 1998, p. 27).

Isso fica evidente a partir da trajetória de Tita na diegese, e como o seu dissabor pela sorte pré-destinada ao nascer irá apresentar consequências em suas relações maternais com as diferentes personagens. Primeiramente, o vínculo com Mamãe Elena - ou a falta dele leva Tita a criar laços de afeto com quem viria a ser a sua figura materna substituta, a nativa Nacha. Em seguida, Esquivel ratifica a tensão entre os lugares do materno quando Tita está magicamente apta para amamentar Roberto quanto Rosaura, sua irmã, é incapaz de 
produzir leite para o filho. E então questiona: "Que Ihe importava o seu destino enquanto pudesse ter por perto de si esse menino, que era mais seu que de ninguém mais. Realmente ela exercia o posto de mãe sem o título oficial" (ESQUIVEL, 1993, p. 66).

Esquivel faz uso "[da] linguagem poética [como] recuperação do corpo materno nos termos da linguagem, um resgate que tem o potencial de romper, subverter e deslocar a lei paterna" (BUTLER, 2016, p. 142) para solapar o entendimento prévio das relações do materno como uma premissa biológica que irá promover laços de afetos entre dois (ou mais) sujeitos. Partindo desse movimento, a autora põe em cheque uma particularidade essencial do que a matriz heterossexualizada (BUTLER, 2016) impõe ao sujeito mulher: ao refutar a noção da maternidade biológica como única e passiva, e propagar uma nova configuração de fazer maternidade a partir de personagens como Nacha e a própria Tita, Esquivel questiona a suposta inerência do comportamento e até do próprio lugar de maternidade. Como água para chocolate coloca em primeiro plano o conceito de maternidade, o desconstrói para então ressignificá-lo, paralelamente à forma como ela faz uso do formato de um livro de receitas - artefato costumeiramente atribuído ao sujeito mulher - para romper com a noção canônica da estrutura de um romance e então quebrar com nossos conceitos prévios do que é um romance - ou o que é, de fato, o lugar do materno.

Mais à frente, na narrativa, Tita é obrigada por sua mãe a providenciar o baquete do casamento de Pedro com sua irmã mais velha, Rosaura; logo em seguida Nacha morre, deixando Tita sem a sua figura materna e de mais expressiva relação de afeto, e consequentemente colocando-a de uma vez por todas para assumir o espaço da cozinha, às ordens de Mamãe Elena; finalmente, o filho de Pedro e Rosaura é levado com os pais para o 
Texas, nos Estados Unidos, e lá acaba morrendo por não ter a nutrição provida por Tita, fazendo com que a protagonista perdesse "[...] todo o interesse na vida [...]" (ESQUIVEL, 1993, p. 71).

Tais desventuras levam Tita a perder seus sentidos, o que ocasiona em sua internação na casa do médico e amigo, o americano John Brown. Entretanto, após Chencha - a empregada da família De la Garza - levar uma sopa para Tita, a antiga receita de Nacha reativa os sentidos e a força da moça através da memória afetiva acionada pela comida:

Aí estavam, junto a Nacha, as brincadeiras de sua infância na cozinha, os caroços de chabacano coloridos, os bolos de Natal, sua casa, o cheiro de leite fervido, [...]. Como the fez bem conversar [...] com Nacha. Igual aos velhos tempos, quando Nacha ainda vivia e juntas haviam preparado uma infinidade de vezes caldo de caudinha. (ESQUIVEL, 1993, p. 102).

Notamos que a cozinha e a comida não mais possuem o peso do enclausuramento e da sujeição, mas agora ganham a função de pulsação de vitalidade e afeto a partir das vivências e das lembranças com Nacha. Tita, ao resgatar "algo [...] valioso: os segredos da vida e do amor através da cozinha" (ESQUIVEL, 1993, p. 198), atribui ao espaço da cozinha um lugar que emana aromas e amores, e não mais o lugar que simboliza a opressão sistematizada promovida por Mamãe Elena.

Após sua melhora durante a estadia na casa de John Brown, Tita jura nunca mais voltar ao rancho da família De la Garza. Isso muda, entretanto, após a morte de Mamãe Elena. Angustiada pelo súbito falecimento da mãe, Rosaura entra em trabalho de parto prematuramente, e assim nasce mais uma mulher destinada a carregar o fardo da tradição De la Garza. A inclinação pela vivência da maternidade - ou a recusa da mesma - por parte 
de Rosaura a posiciona na narrativa como um duplo direto de Mamãe Elena, não só pelas circunstâncias similares a que vieram a ter suas filhas, mas pelo destino que ambas escolhem para elas. Incapaz de prover para sua filha (assim como para seu filho, que morreu por Rosaura não conseguir amamentá-lo), ela perpetua o posicionamento opressor e tradicionalista ao sujeitar sua recém-nascida à mesma violência a que Tita foi subjugada. Percebemos que a ojeriza pela natureza de sujeito materno, provedor de afeto, proteção e alimento, representados por Mamãe Elena e sua filha mais velha, é reforçada pela incapacidade de cuidar de suas respectivas filhas mais novas ao nascer, corroborada na narrativa pela inaptidão das personagens de se relacionar com a comida e com o espaço da cozinha.

Ora, se de acordo com Xavier (1998, p. 65) “[...] a família [é] o espaço por excelência de socialização da mulher - é aí onde começa a se tornar mulher -, isto é, onde as relações de gênero são aprendidas e transmitidas [...]", Tita se encontra decidida a romper com o legado familiar que Ihe impossibilitou existir de forma plena, se recusando a permitir que Pedro batize sua filha com Rosaura de Josefita - nome de Tita -, uma vez que ela "não queria que o nome influísse no destino da menina" (ESQUIVEL, 1993, p. 121), sugerindo então o nome Esperanza, espelhando sua esperança para o fim da opressão e do silenciamento impostos pela dinâmica dos papéis de gênero que consternou as mulheres daquela família por gerações.

Passando a ser um espelho de Mamãe Elena não apenas na convicção da perpetuação das tradições da família, Rosaura se vê impossibilitada de amamentar Esperanza devido ao modo traumático como sua filha veio ao mundo. Assim como Mamãe Elena, Rosaura coloca 
sua filha aos cuidados de Tita que, decidida a irromper com a herança que aterrorizou as mulheres da família por gerações, estimula em sua sobrinha uma nova visão de mundo, aberta a novas possibilidades e novos saberes:

Tita desejava para Esperanza uma educação bem diferente da que Rosaura planejava para ela. De modo que, embora não lhe coubesse, aproveitava os momentos em que Esperanza estava ao seu lado para proporcionar à menina conhecimentos diferentes dos que a mãe lhe dava. Estes momentos constituíam a maior parte do dia, pois a cozinha era o lugar preferido de Esperanza, e Tita sua melhor confidente e amiga (ESQUIVEL, 1993, p. 197).

Notamos, a partir da passagem em destaque, que Esquivel reforça novamente o espaço da cozinha marcado não apenas pelo enclausuramento, mas como espaço de potência da arte e da subversão. Na dinâmica entre Tita e Esperanza, tal circunscrição se projeta também no domínio do afeto, visto que ao ensinar a sua sobrinha os mistérios da vida e da dileção a partir de um espaço em que sua conjuntura se inclina para a sua opressão e silenciamento, ela transmite para Esperanza - assim como foi the passado por Nacha uma perspectiva da cozinha como cerne do saber, do amor e da felicidade.

Ao redefinir o papel da cozinha no núcleo privado - e que aqui acaba reverberando também na vivência dos sujeitos no núcleo público -, Esquivel similarmente rearranja a definição de família, não mais baseada em laços de parentesco, mas a partir de vínculos de afeto. A interdependência entre Tita e Esperanza promove uma ressignificação daquilo que compõe o corpo familiar, uma vez que a tia acolhe a sobrinha na condição de provedora de alimento, de afeto e de proteção contra as amarras que a sociedade conservadora PréRevolucionária - aqui representada por Rosaura - tentou utilizar para sujeitá-la. E se, de acordo com Sceats, "o que as pessoas comem, como e com quem comem, o que elas sentem a respeito da comida e por quE [...] são de crucial importância para entender a sociedade 
humana. A maior significância de comer não é, entretanto, biológica, mas simbólica"3 (SCEATS, 2003, p. 1), essa reconfiguração da noção de maternidade promovida por Esquivel torna-se expressiva no romance uma vez que Mamãe Elena é retratada como um sujeito destituído de benevolência e que simboliza o que há de mais reacionário e opressor na sociedade mexicana Pré-Revolucionária.

Como consequência da insubmissão da protagonista e de seus ensinamentos para Esperanza, o ciclo de abuso, opressão e silenciamento para com as mulheres da família De la Garza finalmente chega ao fim. Ao final do romance, após a morte de Rosaura, Tita e Pedro finalmente se entregam ao amor que Ihes foi negado por quase duas décadas. Essa entrega, incitada pelo banquete do casamento de Esperanza com Alex (filho de John) - e aqui temos um espelhamento invertido do banquete de casamento de Rosaura com Pedro - culmina quando "os corpos ardentes de Pedro e Tita começaram a lançar chispas brilhantes. Estas incendiaram a colcha, que por sua vez incendiou todo o rancho. [...] Lançava pedras e cinza para todo lado, [...] transformando-se em luzes de todas as cores" (ESQUIVEL, 1993, p. 204).

Ao chegar da lua de mel, Esperanza encontra, onde era uma vez o rancho da família De la Garza, o livro de receitas de sua tia em perfeito estado de conservação, que ela passa para sua filha. As receitas de Tita, então, ganham não apenas a incumbência de registro histórico e memorialístico, mas a materialização da conquista de Tita contra o sistema opressor, machista e falocêntrico representado pela tradição familiar, e que agora permite a entrada das mulheres De la Garza na cozinha não por obrigação, mas por prazer.

\footnotetext{
3 "What people eat, how and with whom, what they feel about food and why [...] are of crucial significance to an understanding of human society. The major significances of eating, however, are not biological but symbolic".
} 
Finalmente, é relevante reiterar que, apesar da Revolução Mexicana ser utilizada no romance como pano de fundo, Como água para chocolate tem o seu foco narrativo voltado para a esfera privada, onde o heterocosmo criado pela autora não necessariamente foge da tradição dos romances históricos. Aqui, embora a domesticidade feminina seja o ponto central que move a diegese, tais relações interpessoais possuem a funcionalidade de termômetro para o que estava a acontecer na esfera pública - mais especificamente a Revolução. O romance de Esquivel inova, entretanto, ao se distanciar do lugar comum de onde os discursos são produzidos, trazendo vozes outras - vozes de mulheres - para compor manifestos "paralelos" àqueles produzidos de forma "oficial" - compenetrados por vozes de homens, em sua maioria brancos, heterossexuais e de classe econômica favorável.

Tal inovação toma forma a partir de um duplo movimento no qual, através do uso de receitas - dividindo o romance em meses pontuais durante as décadas que se passaram antes, durante e após a Revolução - a narrativa produz um discurso histórico linear e intermitente, que por sua vez tem sua cronologia solapada quando há a necessidade de rememorar os elos maternais entre as personagens do romance.

Podemos observar esse movimento se materializar com precisão no final do romance, quando a narradora e sobrinha-neta de Tita afirma que, ao voltar de sua lua de mel, Esperanza (sua mãe e filha de Rosaura)

[...] só encontrou sob os restos do que foi o rancho este livro de cozinha que me deixou de herança ao morrer e que narra, em cada uma de suas receitas, esta história de amor enterrada. Dizem que debaixo das cinzas floresceu todo tipo de vida, transformando esse terreno no mais fértil da região (ESQUIVEL, 1993, p. 204) 
Notamos que o queimar do rancho onde viveram gerações da família De la Garza, através da consumação final do amor entre Tita e Pedro, estabelece o desfecho de uma tensão histórica - da família, dos amantes e da História -, assegurando que não há mais espaço para tradições opressoras e silenciadoras se reproduzirem. Isso se torna claro quando a narradora afiança ter uma boa relação com sua mãe, Esperanza: "Por isso estou preparando tortas de Natal, meu prato favorito. Mamãe me preparava todos os anos. Minha mãe!... Como sinto falta de seu tempero, do sabor de seus pratos, do cheiro de sua cozinha, [...] de suas tortas de Natal!" (ESQUIVEL, 1993, p. 204-5).

Percebemos que, ao mencionar a torta de Natal, a narradora remete não só ao paralelo com sua tia-avó, que foi estabelecido desde o primeiro capítulo quando ela afirma que "Mamãe dizia que [...] eu era tão sensível à cebola quanto Tita, minha tia-avó" (ESQUIVEL, 1993, p. 3), mas ao rememorar a receita que nomeia tal capítulo, ela reforça a ciclicidade das histórias e da História, que se repetem e se transforam com o passar das gerações. Entretanto, a autora nos mostra, ao final de seu romance, que esse ciclo é rompido uma vez que a narradora e sua mãe desfrutam de uma relação maternal amorosa e saudável. Podemos entender que isso se dá como uma consequência do posicionamento de resistência e de subversão de Tita frente à opressão e ao silenciamento das tradições e da sociedade que morreu com Mamãe Elena, e que essa nova configuração de afetos e de maternidade "[...] continuará vivendo enquanto houver alguém que cozinhe suas receitas" (ESQUIVEL, 1993, p. 205).

\section{REFERÊNCIAS}


ABARCA, Meredith. Voices in the kitchen: views of food and the world from working-class Mexican and Mexican American women. Texas: Texas A \& M University Press, 2006.

BADINTER, Elisabeth. Um amor conquistador: o mito do amor materno. Trad. Waltensir Dutra. Rio de Janeiro: Nova Fronteira: 1985.

BARTHES, Roland. O prazer do texto. Trad. J. Guinsburg. São Paulo: Perspectiva, 2015.

BEAUVOIR, Simone de. O segundo sexo: 2. a experiência vivida. Trad. Sérgio Milliet. São Paulo: Difusão Européia do Livro, 1967.

BUTLER, Judith. Problemas de gênero: feminismo e subversão de identidade. Trad. Renato Aguiar. ed. 10. Rio de Janeiro: Civilização Brasileira, 2016.

DEL PRIORE, Mary. Ao sul do corpo: condição feminina, maternidade e mentalidade no Brasil Colônia. São Paulo: Editora UNESP, 2009.

HEITMEYER, Wilhelm, et al (ed). Control of violence: historical and international perspectives on violence in modern societies. New York: Springer, 2011.

ROCHA-COUTINHO, Maria Lúcia. Tecendo por trás dos panos: a mulher brasileira nas relações familiares. São Paulo: Rocco, 1994.

SCEATS, Sarah. Food, consumption and the body in contemporary women's fiction. Cambridge: Cambridge University Press, 2003.

WOOLF, Virginia. Um teto todo seu. Trad. Bia Nunes de Sousa, Glauco Mattoso. São Paulo: Tordesilhas, 2014.

XAVIER, Elódia. Declínio do patriarcado: a família no imaginário feminino. Rio de Janeiro: Editora Rosa dos Tempos, 1998.

Artigo recebido em: 14 de março de 2018. Artigo aprovado em: 29 de agosto de 2018. 